\title{
The evaluation of a new highly specialist psychologist working with high risk patients in an acute mental health inpatient setting.
}

\begin{abstract}
Objectives: The aim of this service evaluation was to evaluate the function and impact of a highly specialist psychologist working with high risk patients on an acute mental health inpatient setting. The impact was examined on outcomes such as risk related incidents, readmission, average length of stay, and use of restrictive practice.

Method: A mixed methods pilot service evaluation was undertaken to examine the impact of the specialist psychologist role on these outcomes over a 17-month period. Demographic and clinical data was collected for 18 patients who were seen by the psychologist. Routinely collected clinical data examining risk incidents, readmission rates, average length of stay, and use of restrictive practice, were also utilised to evaluate outcome across the evaluation period (at baseline and sixmonth follow-up).
\end{abstract}

Results: The specialist psychologist inputted to 18 patient's care and undertook a variety of direct and indirect work and training. Examination of descriptive routine clinical data indicated a slight reduction in risk related incidents, readmissions, and average length of stay after the introduction of the psychologist role, however these were not significant.

Conclusions and implications for practice: These initial findings some initial reductions in outcomes, but these were not significant. Further, more robust research is required to see if such a role can have significant impacts on outcomes.

Key words: acute inpatient; psychiatric hospital; psychological intervention; risk management, personality disorder.

Impact and implications: A specialist psychologist with expertise in working with people presenting with high risk behaviours can improve clinical outcomes and restrictive practices. This would suggest that employing psychological staff to work with patients with high risk behaviours may be beneficial. More specifically the promotion of indirect, such as consultation and training, based on psychological formulation for the purposes of risk management should be considered. 


\section{Introduction}

People presenting in mental health inpatient services usually have complex needs and experience high levels of distress which, for some, can lead to engaging in behaviours that pose a risk of harming themselves or others. Mental health professionals are seen as responsible for assessing and managing this risk within an inpatient setting (Bowers, 2014; O'Rourke \& Bailes, 2006). However, rather than considering a holistic approach to understanding and working with people's needs, 'risk' is often associated only with 'dangerousness', leading to reactive interventions (McGeorge \& Rae, 2007; Duxbury et al, 2019), characterised by rigidity, excessive controls, avoidance, complacency or the denial of risk (O'Rourke \& Bailes, 2006; Duxbury et al., 2019). This is despite recommendations that risk management should be based upon a thorough risk assessment and formulation (Royal College of Psychiatry, 2017). In particular, people diagnosed with personality disorders form one of the largest patient groups within this setting, and are the patient group that staff report find most challenging in terms of managing risk behaviours (Weight \& Kendal, 2013; Bodner et al., 2015).

A report on the state of care in current NHS mental health services (Care Quality Commission, 2017) highlighted concerns that unnecessary and excessive restrictions and security measures are still persistent in inpatient wards, involving the frequent use of enhanced observations, seclusion, restraint and rapid tranquillisation. These practices involve severe restrictions of people's liberties, dignity and rights, and a custodial-like relationship with clinicians. Problematically, therapeutic and psychosocial interventions, which could reduce the use of restrictive practices, continue to be regularly unavailable (Pilgrim \& McCrainie, 2013, p.107). The Department of Health (DoH, 2007) highlights the need for multidisciplinary risk management that include bio-psycho-social contributions and aim at building upon a person's strengths and recovery. They also state the importance of minimising the use restrictive practices and instead using preventative strategies, such as the development of proactive environments and person-centred care interventions (DoH, 2014, 2015).

Psychological interventions play an important role in risk management. Current National Institute of Health and Care Excellence (NICE, 2009, 2014) guidelines recommend accessing evidence-based psychological interventions during the acute phase of mental distress and after a crisis period. Both indirect, such as psychological consultation and case formulation meetings, and direct psychological interventions, individual and group therapy, have been demonstrated to contribute to risk management. For example, research has demonstrated that psychosocial formulations can be helpful in developing a ward culture which is compassionate, and understanding of people's presentations and behaviours (Berry, Barrowclough, \& Wearden, 2009). Berry, Barrowclough \& Wearden (2009) delivered a case-formulation group to 30 inpatient staff, and found a significant reduction in client blame, and an increase in staff's perceived control in managing patient's mental health following the 
group. Moreover, understanding the self-protective or self-regulatory functions of behaviours can lead to more exploratory and compassionate responses from staff (Bowers, 2014). Ward-based psychological input also appears to have a positive impact on clinical outcomes, length of stay, reductions in medication and relapse rates (Berry et al., 2016). Individual psychological interventions in inpatient wards and various psychological approaches appear effective in minimising risk (Clarke \& Wilson, 2008; Schramm et al., 2007). For example, dialectical behavioural therapy (DBT) and cognitive behavioural therapy (CBT) have both shown positive results in reducing suicide ideation and attempts (Linehan et al., 2015; Tarrier et al, 2008), self-harming (Linehan et al., 2015) and violent behaviour (Evershed et al, 2003; Haddock et al., 2009) in people with severe and enduring mental health difficulties. In particular, research has demonstrated that long admissions are not helpful to those with a diagnosis of personality disorder. It has been outlined that in some circumstances they can be detrimental and worsen mental health (Paris, 2017). Thus, a robust psychological formulation and intervention may facilitate the team to take positive risks and proactively discharge patients.

Through recent contract negotiations with commissioners the trust was awarded funding from the Parity of Esteem Programme (Mitchell, Hardy \& Shiers, 2017; North East London NHS Foundation Trust, 2017). A proposal was then made for the development of the specialist psychologist's role to firstly improve the provision offered to those with high risk presentations in an inpatient context. High risk presentations were defined as patients who (a) had at least three admissions in the last 18-months, (b) had a high-risk behaviour (self-harm, suicidality, violence or aggression) which was not reducing despite routine acute inpatient care, and (c) more than a 12-week stay on the acute inpatient ward. Patients had to meet at least one of these criteria to be seen by the specialist psychologist. The specialist psychologist has been in post since November 2017 working at AfC band 8a 0.6WTE across the five wards with patients identified as high risk referred either by the ward psychologist or during team meetings. These service users are then escalated for discussion by the directorate's leadership team (North East London NHS Foundation Trust, 2017). A series of duties and responsibilities were developed for the role (Appendix 1), underpinned by the UCL competence framework for working with people with a personality disorder diagnosis and psychosis diagnosis respectively (Roth \& Pilling, 2013a, Roth \& Pilling, 2013b). This included both direct clinical work, indirect work and staff training. The psychologist received fortnightly supervision from a psychologist with expertise in working within inpatient settings and psychosis, and monthly supervision from a specialist psychologist and academic specialising in DBT and personality disorders.

The present study aimed to examine the usefulness of the introduction of a new highly specialist psychologist working with high risk patients (referred to henceforth as the specialist psychologist) 
role in an acute mental health inpatient setting. More specifically, this study aimed to examine the function and impact of the specialist psychologist by answering the following research questions:

1) What is the function of the specialist psychologist? More specifically, who is referred to the specialist psychologist and what type of work is undertaken? What are the referral rates and consent rates of patients for the specialist psychologist?

2) What is the impact of a newly employed specialist psychologist on an inpatient mental health ward? Does the role have an effect on:

a. The number, type and severity of risk related incidents reported

b. The number of re-admissions

c. The average length of stay of patients

d. Ward staff's approach to risk management 


\section{Methodology}

\section{Study design}

A mixed-methods (pre and post) service evaluation was conducted to examine the impact and function of a highly specialist psychologist working with high risk acute mental health inpatients. The service evaluation utilised routinely collected data on individual patients referred to the specialist psychologist as well as service-level data for the wards. Data was collected over a 17-month pilot period (February 2017 - July 2018). As this was a service evaluation, NHS ethical approval was not required. However, local trust Research and Development approval was granted to conduct this service evaluation and reviewed the proposal. The service evaluation also adhered to best practice principles of informed consent, confidentiality, and minimising risk as outlined in the British Psychological Society's (BPS) code of human research ethics (2014).

\section{Service context}

This service evaluation was carried out within five inpatient mental health wards in an outer London Borough. These wards provide care for male and female adults who are experiencing an acute mental health crisis and may be at risk of harm to themselves or others. Ward teams are multi-disciplinary and include psychiatrists, nurses, support workers, occupational therapists, psychologists and assistant psychologists. In addition to the highly specialist psychologist, the 20-bedded wards had a 0.4 Whole Time Equivalent (WTE) qualified psychologist (agenda for change [AfC] band 8a), and 1.0WTE of an assistant psychologist.

\section{Data collection and procedure}

In order to under the function of the specialist psychologist role, individual-level patients data was included in the analysis, including: number of patients referred, number of patients seen, demographics of patients seen (age, gender, ethnicity, diagnosis), individual level clinical information (referral reason, number of admissions, mental health act status, observation levels, high risk register status), and type of therapeutic input.

The evaluation of the global impact, i.e. the impact of the specialist psychologist input (direct, indirect and training) on the broader ward environment, was conducted through the examination of two routinely collected clinical data-sets:

1. A dataset, held and monitored by the Quality \& Patient Safety Trust department, including all the 'risk- related incidents' recorded on Datix (i.e. incident reporting software used within the trust) for the two of wards was utilised. Only the two female acute ward's datasets were utilised as the 
specialist psychologist saw the majority of patients (72\%) on this ward, and therefore they were most likely to be sensitive to change. This dataset included categorical data on three different variables regarding the risk incidents documented: category (abuse of patient by patient, abuse of patient by staff, abuse of staff by patient, self-harm), severity (no harm, minor, moderate, severe) and detail of event (e.g. attempted suicide, physical abuse). The dataset also included a qualitative description of the action taken by ward staff in response to the incident. The dataset was divided in two sets to enable comparison: one set including data for the six months prior to the introduction of the role (June to November 2017) and the second set including data for the six months after the role was introduced (December 2017 to May 2018). There were a total of 348 risk reports from June to November 2017 and 300 from December to May 2018.

2. The second dataset set, sourced by the Trust Performance Team, included patients across the five acute ward who were readmitted within 90 days of discharge. This data was compared for a period of time before the introduction of the specialist role (February to July 2017) and the same period on the following year (February to July 2018), after the role had been introduced. There were a total of 136 patients included in the first database and 96 patients in the second database. The total average length of stay for each cohort was also provided. However, the length of stay for each individual patient was not provided.

\section{Data Analysis}

All statistical analyses were performed using SPSS for Windows 22.0. Descriptive statistics were used to examine the quantitative data in the data-sets. Normality was checked through the examination of skewness and kurtosis. Paired t-tests were performed to determine whether the changes observed in ALoS and use of restrictive practices were statistically significant. To determine significance, a $\mathrm{p}<0.05$ level was used.

A deductive content analysis, following Hsieh \& Shannon's guidelines (2005), was conducted by author CA and checked by LW to evaluate the descriptions of the actions taken in response to a riskrelated incident (included in dataset 1). Prior formulated categories were applied (Mayring, 2000) which were based on existing literature and guidelines concerning the management of risk in inpatient mental health settings (James, Bowers \& Van Der Merwe, 2011; NICE, 2015). These initial categories included: 1. Low level intervention (e.g. communication, distraction, etc.); 2. Enhanced observations; 3. Seclusion; 4. Manual restraint; 5. Mechanical restraint; 6. Rapid tranquillisation. The dataset was then reviewed, highlighting all text that appeared to describe staff's responses to a riskrelated incident. The predetermined categories were then systematically assigned to the highlighted text. Text that could not be coded into one of the six categories was assigned another label that captured the essence of the risk management approach. The final list of categories found in the dataset 
were inputted together within a coding schedule (Appendix 1) which includes definitions and examples for each category, determining under what circumstances a text passage was coded with a category. Because the study design and analysis did not result in coded data that could be compared meaningfully using statistical tests of difference, comparisons of relative frequency of codes were performed (Atkisson, Monaghan \& Brent, 2010). 


\section{Results}

\section{What is the demographic profile of patients seen by the specialist psychologist?}

A total of eighteen patients were included in the analysis. The age of patients referred ranged from 18 to 66 years $(M=29, S D=10.8)$. The majority of patients presented with a diagnosis of personality disorder (61\%), were female (72\%), white British (89\%), were under section of the Mental Health Act (72\%), and on general observation, i.e. the minimum acceptable level of observation where the patient's whereabouts is known at all time (50\%). Demographic and clinical information is presented in Table 1.

[INSERT TABLE 1 HERE]

\section{What did the specialist psychologist role involve?}

The specialist psychologist had capacity to see six to eight patients a week over a six-month period (approximately 36 patients across the six-month period) but only eighteen patients were referred to the specialist psychologist between November 2017 to July 2018. As this was a new role, the initial patients referrals were low but increased over the six month period. A total of 18 patients were referred during that time period. Fifteen patients were willing to engage, two refused and for one patient the input was only through consultation with the ward psychologist.

The specialist psychologist's direct work with patients included engagement ( $\mathrm{n}=8 ; 44 \%)$, assessment and formulation $(n=11 ; 61 \%)$, intervention $(n=4 ; 22 \%)$ and discharge planning $(n=3 ; 17 \%)$. All of the participant's input from the specialist psychologist focused on reducing risk (100\%). The mean average number of direct sessions was 4.05 (SD: 4.01; range $1-15$ ). Sessions mostly took place on a weekly basis $(n=14 ; 78 \%)$ and the average session length was 47 minutes (range 15-60).

In regard to interdisciplinary work, indirect work and consultation, all patients (100\%) had at least one joint sessions with the specialist psychologist and ward staff members. Work with most patients involved liaison/joint working with the ward psychologist ( $\mathrm{n}=14 ; 78 \%)$. Work with 8 (44\%) patients also involved consultation with other staff members (i.e. ward manager, psychiatrist, and nursing staff).The specialist psychologist also attended professionals meetings for 8 (44\%) patients and ward rounds for $9(50 \%)$ patients. Family sessions were held for 4 patients. Reports were written and fed back to the team for $6(33 \%)$ patients. Other indirect work included holding a Multi-Disciplinary Team (MDT) formulation session $(\mathrm{n}=1 ; 6 \%)$ and providing supervision for an assistant psychologist who was working with a high risk patient $(\mathrm{n}=1 ; 6 \%)$. In addition, the specialist psychologist also provided two three-hour training sessions for the five acute ward on managing challenging behaviour, 
underpinned by the "Meeting the challenge, making the difference" guidelines for working with personality disorder (Bolton, Lovell, Morgan, \& Wood, 2014).

\section{What was the impact of the specialist psychologist?}

The number of risk-related incidents reported at the follow-up time period (December 2017 to May 2018; $\mathrm{n}=300$ ) was $14.8 \%$ lower than at the baseline time period (June 2017 - November $2018 \mathrm{n}=348$ ). A complete table of results is presented in the supplementary material (table 5). There was a reduction in the number of self-harm related incidents (from $42.5 \%$ to $28.7 \%$ ) while the incidents of abuse of patient by patient increased (from $25.9 \%$ to 55.3\%). Similarly, differences were found on 'detail of event' frequencies, with an increase in incidents (from 33\% to 51.7\%) documented as 'physical abuse, assault or violence' following the introduction of the specialist psychologist and a reduction in incidents recorded as 'attempted suicide' (from 35.6\% to 8.7\%) and 'self-harming behaviour' (from $20.1 \%$ to $11.3 \%$ ). No other significant differences in the type, severity or detail of event were found.

There was a $29.4 \%$ decrease in the total average number of re-admissions from Time 1 (February to July 2017; $\overline{\mathrm{x}}=22.7$; SD $16.5 ; 15-44 ; \mathrm{N}=136$ ) to Time 2 (February to July 2018; $\overline{\mathrm{x}}=16$; SD 13.8; 8 39; $\mathrm{N}=96$ ). Visual inspection of the data, presented in Table 2, suggests there was a reduction in all the wards except for Male Ward 2.

[INSERT TABLE 2 HERE]

The AloS data is presented in Figure 1. Performing a independent samples t-test analysis found the difference between Time 1 ( $\overline{\mathrm{x}}=23.2, \mathrm{SD}=3.55$; February - July 2017) and Time $2(\overline{\mathrm{x}}=20.7, \mathrm{SD}=3.98$ February - July 2018) not to be statistically significant; $t(8)=2.057, \mathrm{p}=0.322$.

\section{[INSERT FIGURE 1 HERE]}

A deductive content analysis was used to categorise staff's actions in response to risk-related incidents. As the specialist psychologist had most input on both the female wards due to $78 \%$ of participants being from those wards, only the female ward data was used to examine the broader impacts of the role on staff's approaches to risk management. Results are presented in Table 3. Visual inspection of relative frequencies (i.e. the fraction of times a category was reported at each particular time and ward) suggested there were no significant differences between Time 1 and Time 2 in the type of actions taken to manage risk-related incidents. Nonetheless, when combining the categories involving restrictive practices (i.e. enhanced observations, restraint and rapid tranquilisation), a $24 \%$ overall reduction was found in the number of times a restrictive category was recorded in Time 2 $(n=228,76 \%$ of total responses recorded) when compared to Time $1(n=289,83 \%)$ (Figure 2). 
However, the difference between Time $1(\overline{\mathrm{x}}=48.2 ; \mathrm{SD}=15.32)$ and Time $2(\overline{\mathrm{x}}=38 ; \mathrm{SD}=12.52)$ did not reach statistical significance; $\mathrm{t}(5)=1.51, \mathrm{p}=0.19$.

\section{[INSERT TABLE 3 HERE] \\ [INSERT FIGURE 2 HERE]}

\section{Discussion}

The work undertaken by the specialist psychologist during the evaluation period was in line with the duties and responsibilities designed for the role (supplementary material). The specialist psychologist's work particularly involved engagement, assessment and formulation while their input on intervention, discharge planning and report writing was more limited. However, only eighteen people were referred and, for some, involvement may have still been on the initial stages.

Most of the people referred for specialist psychologist's input were women which coincides with national statistics for Borderline Personality Disorder (70\% of people diagnosed are women; Mind, 2010). The existence within the service of a male Psychiatric Intensive Care Units, already providing specialist care to a proportion of male patients identified as 'high risk', may also explain the low number of male patients referred. Interestingly, the majority of people referred were White-British (89\%) which does not represent the ethnic diversity present in these wards. Moreover, suicide rates are currently between 2 and 3 times higher among people from black and minority ethnic (BME) groups. Particularly, women aged 25-39 from ethnic minorities are much more likely to die by suicide than White-British women of the same age (Britain, 2011). It would be important to explore the reasons for the low number of referrals for BME people as it appears to contradict government policies (e.g. DoH, 2011) which urge services to ensure equal access to interventions and resources. This finding, however, is in line with studies showing that BME service users are still underrepresented in clinical psychology services (Williams et al., 2006) and more likely to be offered medication than talking therapies (Singh \& Clarke, 2006).

The literature has suggested that psychological interventions within an acute inpatient ward can reduce risk-related incidents, readmission and ALoS (e.g. Berry et al., 2016). Descriptive data analysis in this current study revealed some reductions in reduction in risk-related incidents, readmission and ALoS, keeping in line with the existing evidence. This evaluation found that restrictive practices were used as a response to risk incidents $86 \%$ of the time before the introduction of the specialist psychologist and $76 \%$ after, although not a significant change. These are surprisingly high figures given that current guidelines (DoH, 2014, 2015) have set an expectation to minimise these practices. Research shows that the use of restrictive practices is often linked to staff lack of knowledge and skills in managing risk behaviours (Lamb, Sibbald \& Stirzaker, 2018). The literature 
has stated that providing training, consultation and formulation sessions, can reduce restrictive practice use (Royal College of Psychiatry, 2017). The specialist psychologist did not have a significant impact on the restrictive practice but longer-term psychological training is likely needed to bring about a reduction. Further research is required to determine if a specialist psychologist role can bring about such change.

The outcomes evaluated in this service evaluation were primarily guided by service management's and stakeholders' needs and interests. However, while service delivery and commissioning decisions are largely based on quantitative data, there is an increasing emphasis on considering patients' views and experiences (Glasby \& Beresford, 2006) and current guidance (DoH, 2008) states that the evaluation of care quality must address patient experience, alongside safety and clinical effectiveness. Therefore, including patients' perspectives in the development and evaluation of the role would have been vital in ensuring patient needs were met. While this was initially considered, this study was subject to the challenges of doing research in inpatient settings previously documented (Owen, Sellwood, Kan, Murray \& Sarsam, 2015). Patients' high levels of distress made it, in some cases, inappropriate to complete the outcome measures or qualitative interviews initially considered. Further barriers included sudden discharges or refusal to engage as well as other commitments of the specialist psychologist which limited the clinical work conducted and, in turn, the data collected. It may be helpful for future studies to embed evaluation measures as part of patients' discharge planning process.

While the small group of people who received the specialist psychologist's input is a limitation, the analysis has provided some useful insights into the work of a single specialist psychologist in a ward setting. This service evaluation could be replicated extending the period of the evaluation or the number of specialist psychologists evaluated which would give a better indication of the role and its impact. Findings and recommendations from this evaluation are specific and cannot be readily extrapolated to similar input provided by other therapists within other services.

The service evaluation was also restrained by service requirements and available data. As this was a pilot workforce initiative, the post was only initially funded for 12 months, and feedback to the funders was required at 6-months, which only allowed for a limited evaluation period. It is suggested that culture change and service transformation may take several years (Gilburt \& Peck, 2014) and it is difficult to ascertain if the selected time period is representative of a typical period within the service. The study was limited by the use of routinely collected data as a means to evaluate outcomes, and therefore may not have been the most appropriate data to examine the impact of the role. Another limitation was that there were limited referrals from the inpatient team, due to their unfamiliarity with the new role. The outcome data evaluated (i.e. re-admissions, ALoS, risk incidents) are influenced by 
multiple systemic factors, which often fluctuate within a ward environment. While the study was being conducted, the service underwent substantial changes, including marked changes in staffing and ward structure, which may have changed the form of support provided and staff's morale in turn impacting on the outcomes evaluated in this study. Relatedly, the specialist psychologist's input varied patient to patient, and no one patient received similar input, making it a challenge to link outcomes to the specialist psychologist's role. Moreover, the two datasets collected data over two different time periods as we were limited to routinely collected data used within our acute directorate, which also makes them unmatched. The pre-post data for one of the datasets was collected at different times of the year due to the 6-month timeframe set by funders. Therefore, due to the large number of potential confounding variables, any influence of the specialist psychologist on readmissions, ALoS, risk incidents and restrictive practices are difficult to discern. This inability to control for confounding variables reduces the reliability of the results, and therefore all data presented should be interpreted with caution. Research should increase its reliability by focusing on change and tracking progress. It could thus be useful to re-visit these outcomes relatively soon in order to investigate whether results differ. As data used for this evaluations is routinely collected by the service this should be simple to implement. In order to reduce cohort effects and confounding factors, future researchers may wish to compare outcomes among service users who have accepted the specialist psychologist's input and those who have refused or among wards that have specialist psychologist's input and those that do not. Finally, data used in this evaluation was recorded directly by ward staff which may raise questions regarding its objectivity. Potential biases may have included, for example, that staff may have avoided, for fear of being blamed or criticised, documenting situations not compliant with guidelines or evidence-based practice.

There are a number of clinical implications arising from this research. This service evaluation provides some initial tentative data to suggest that having a specialist psychologist working with patients with high risk presentations and the ward teams may have some positive impacts on clinical outcomes and restrictive practices. However, these findings need to be interpreted with caution due to methodological limitations. This would indicate that employing psychological staff or skilling up existing staff with the skills to work with high risk patients with a personality disorder could have important benefits for acute mental health inpatient settings. More specifically the promotion of psychological formulations for the purposes of risk management should be prioritised, which can be achieved through consultation, discussions and formulation meetings with the MDT. Psychologically informed, person-centred approaches to risk management are also important. This may involve the provision of further training to ward staff on using psychosocial models and interventions to working with patients' risk-related behaviours. The implementation of this unique role needs further exploration. Recommendations for further evaluations include conducting a rigorous feasibility trial of the psychologist's role so more definitive findings can be identified. 


\section{References}

Atkisson, C., Monaghan, C., \& Brent, E. (2010). Using computational techniques to fill the gap between qualitative data analysis and text analysis. Kwalon, 15(3), 6-20.

Berry, K., Barrowclough, C., \& Wearden, A. (2009). A pilot study investigating the use of psychological formulations to modify psychiatric staff perceptions of service users with psychosis. Behavioural and Cognitive Psychotherapy, 37(1), 39-48.

Berry, K., Haddock, G., Kellett, S., Roberts, C., Drake, R., \& Barrowclough, C. (2016). Feasibility of a ward-based psychological intervention to improve staff and patient relationships in psychiatric rehabilitation settings. British Journal of Clinical Psychology, 55(3), 236-252.

Bodner, E., Cohen-Fridel, S., Mashiah, M., Segal, M., Grinshpoon, A., Fischel, T., Iancu, I. (2015) The attitudes of psychiatric hospital staff towards hospitalisation and treatment of patients with borderline personality disorder. BMC Psychiatry, 2, 1-12, DOI 10.1186/s12888-014-0380-y

Bowers L. (2014). Safewards: a new model of conflict and containment on psychiatric wards. Journal of Psychiatric and Mental Health Nursing, 21(6), 499-508. 
Britain, G. (2011). No health without mental health: a cross-government mental health outcomes strategy for people of all ages. London: Stationery Office.

British Psychological Society (2014). Code of Human Research Ethics. Leicester: BPS. Retrieved from: http://www.bps.org.uk/what-we-do/ethics-standards/ethics-standards (accessed on 13 October 2018).

British Psychological Society (2012). Commissioning and Delivering Clinical Psychology in Acute Adult Mental Health Care Guidance for Commissioners, Service Managers, Psychology Managers \& Practitioners. Leicester: BPS. Retrieved from http://shop.bps.org.uk/commissioning-and-deliveringclinical-psychology-in-acute-adult-mental-health-care.html (accessed 10 October 2018).

Care Quality Commission (2018). Adult inpatient survey. London: National Centre for Social Research. Retrieved from https://www.cqc.org.uk/sites/default/files/20180613 ip17 statisticalrelease.pdf (accessed 17 October 2018).

Care Quality Commission. (2017). The state of care in mental health services 2014 to 2017. Care Quality Commission, Newcastle-upon-Tyne, available at: www. cqc. org. uk/sites/default/files/20170720_stateofmh_report.pdf [Google Scholar].

Clarke, I. \& Wilson, H. (Eds) (2008). Cognitive Behaviour Therapy for Acute Inpatient Mental Health Units: Working with Clients, Staff and the Milieu. London: Routledge.

Department of Health (2007). Best Practice in Managing Risk. London: Department of Health.

Department of Health. (2011). No health without mental health: A cross-government mental health outcomes strategy for people of all ages. London: Department of Health.

Department of Health. (2008). High Quality Care For All: NHS next stage review final report. London: The Stationary Office.

Department of Health (2014). Positive and Proactive Care: reducing the need for restrictive interventions. London: Department of Health.

Department of Health (2015). Mental Health Act 1983: Code of Practice. London: TSO.

Duxbury, J., Baker, J., Downe, S., Jones, F., Greenwood, P., Thygesen, H., McKeown, M., Price, O., Scholes, A., Thomson, G., Whittington, R. (2019) Minimising the use of physical restrain in acute mental health services: The outcome of a restraint reduction programme ('REsTRAIN YOURSELF') 
Evershed, S., Tennant, A., Boomer, D., Rees, A., Barkham, M., \& Watson, A. (2003). Practice-based outcomes of dialectical behaviour therapy (DBT) targeting anger and violence, with male forensic patients: A pragmatic and non-contemporaneous comparison. Criminal Behaviour and Mental Health, 13(3), 198-213.

Gilbert, P. (2009). Introducing compassion-focused therapy. Advances in Psychiatric Treatment, 15(3), 199-208.

Gilburt, H. \& Peck, E. (2014). Service transformation: Lessons from mental health. London: The King's Fund.

Glasby, J., \& Beresford, P. (2006). Commentary and Issues: Who knows best? Evidence-based practice and the service user contribution. Critical Social Policy, 26(1), 268-284.

Haddock, G., Barrowclough, C., Shaw, J. J., Dunn, G., Novaco, R. W., \& Tarrier, N. (2009). Cognitive-behavioural therapy v. social activity therapy for people with psychosis and a history of violence: randomised controlled trial. The British Journal of Psychiatry, 194(2), 152-157.

Hsieh, H. F., \& Shannon, S. E. (2005). Three approaches to qualitative content analysis. Qualitative Health Research, 15(9), 1277-1288.

James, K., Bowers, L., \& Van Der Merwe, M. (2011). Self-harm and attempted suicide in psychiatric inpatient care: a literature review. Institute of Psychiatry at the Maudsley.

Lamb, N., Sibbald, S., \& Stirzaker, A. (2018). Shining lights in dark corners of people's lives: Reaching consensus for people with complex mental health difficulties who are given a diagnosis of personality disorder. Criminal Behaviour and Mental Health, 28(1), 1-4.

Linehan, M. M., Korslund, K. E., Harned, M. S., Gallop, R. J., Lungu, A., Neacsiu, A. D., ... \& Murray-Gregory, A. M. (2015). Dialectical behavior therapy for high suicide risk in individuals with borderline personality disorder: a randomized clinical trial and component analysis. JAMA Psychiatry, 72(5), 475-482.

Mayring, P. (2000). Qualitative content analysis. Forum: Qualitative Social Research,1(2).

McGeorge, M., \& Rae, M. (2007). Acute in-patient psychiatry: Service Improvement-The time is now. Psychiatric Bulletin, 31(7), 259-261.

Mind, 2010, Understanding borderline personality disorder. London: Mind. Retrieved from http://www.mind.org.uk/help/diagnoses_and_conditions/personality_disorders. (accessed 5 October 2018). 
Mitchell, A. J., Hardy, S., \& Shiers, D. (2017). Parity of esteem: addressing the inequalities between mental and physical healthcare. BJPsych Advances, 23(3), 196-205.

National Institute for Health \& Clinical Excellence (2014). Psychosis and schizophrenia in adults: prevention and management (NICE Guideline No. 178). London: National Institute for Health and Clinical Excellence.

National Institute for Health and Care Excellence (2015). Violence and aggression: Short-term management in mental health, health and community settings: Updated edition. London: British Psychological Society.

National Institute for Health and Clinical Excellence (2009). The Treatment and Management of Depression in Adults (NICE Guideline No. 90). London: National Institute for Health and Clinical Excellence.

National Research Ethics Service (2006). Differentiating audit, service evaluation and research. London: NHS Health Research Authority.

O'Rourke, M. and Bailes, G. (2006). Risk Assessment and Management. British Psychological Society Position Paper, UK. Retrieved from https://www1.bps.org.uk/system/files/Public\%20files/DCP/cat-381.pdf

Paris, J. (2017) Stepped care for borderline personality disorder: making treatment brief, effective, and accessible. Cambridge. Academic Press.

Pilgrim D. \& McCrainie A. (2013). Recovery and Mental Health: a critical sociological account. Basingstoke: Palgrave Macmillan.

Roth, A. D and Pilling, S. (2013). A competence framework for psychological interventions with people with personality disorder. London: Research Department of Clinical, Health and Educational Psychology, University College London.

Royal College of Psychiatrists (2017). Accreditation for Inpatient Mental Health Services (AIMS) Standards for Inpatient Wards - Working-age Adults. London: The Royal College of Psychiatrists' Centre for Quality Improvement.

Royal College of Psychiatrists (2017) Managing Risk. London: Royal College of Psychiatry Schramm, E., van Calker, D., Dykierek, P., Lieb, K., Kech, S., Zobel, I., Leonhard, R. \& Berger, M. (2007). An intensive treatment program of interpersonal psychotherapy plus pharmacotherapy for depressed inpatients: acute and long term results. The American Journal of Psychiatry, 164, 768-77. 
Tarrier, N., Taylor, K., \& Gooding, P. (2008). Cognitive-behavioral interventions to reduce suicide behavior: a systematic review and meta-analysis. Behavior Modification, 32(1), 77-108.

Taylor, K. N., \& Sambrook, S. (2012). CBT for culture change: formulating teams to improve patient care. Behavioural and Cognitive Psychotherapy, 40(4), 496-503.

Tulloch, A. D., David, A. S., \& Thornicroft, G. (2016). Exploring the predictors of early readmission to psychiatric hospital. Epidemiology and Psychiatric Sciences, 25(2), 181-193.

Walsh, J., \& Boyle, J. (2009). Improving acute psychiatric hospital services according to inpatient experiences. A user-led piece of research as a means to empowerment. Issues in Mental Health Nursing, 30(1), 31-38.

Weight, E.J., Kendal, S. (2013) Staff attitudes towards inpatients with borderline personality disorder. Mental Health Practice, 17 (3), 34 - 38

North East London NHS Foundation Trust. (2017). 17/19 Investment in Crisis Pathway and Mental Health Inpatient Services for BHR CCGs. London: National Health Service.

North East London NHS Foundation Trust. (2017). High Risk Client Reporting Protocol. London: National Health Service. 
Table 1. Demographic characteristics of patients referred to the specialist psychologist $(N=18)$

\begin{tabular}{|c|c|c|c|}
\hline Demographic & Characteristic & $\mathbf{N}$ & $\%$ \\
\hline Gender & $\begin{array}{l}\text { Female } \\
\text { Male }\end{array}$ & $\begin{array}{l}13 \\
5\end{array}$ & $\begin{array}{l}72 \\
28\end{array}$ \\
\hline Ethnicity & $\begin{array}{l}\text { White } \\
\text { Black } \\
\text { Asian } \\
\text { Mixed }\end{array}$ & $\begin{array}{l}16 \\
1 \\
1 \\
0\end{array}$ & $\begin{array}{l}89 \\
5.5 \\
5.5 \\
0\end{array}$ \\
\hline Diagnosis & $\begin{array}{l}\text { Psychotic disorders } \\
\text { Personality disorders } \\
\text { Bipolar affective disorder } \\
\text { Depressive disorder }\end{array}$ & $\begin{array}{l}5 \\
11 \\
1 \\
2\end{array}$ & $\begin{array}{l}28 \\
61 \\
5.5 \\
11\end{array}$ \\
\hline $\begin{array}{l}\text { Number of admissions (last } \\
18 \text { months). }\end{array}$ & $\begin{array}{l}1 \\
2 \\
3 \\
4 \\
>5\end{array}$ & $\begin{array}{l}5 \\
6 \\
2 \\
1 \\
4\end{array}$ & $\begin{array}{l}28 \\
33 \\
11 \\
5.5 \\
22\end{array}$ \\
\hline $\begin{array}{l}\text { Level of observation at the } \\
\text { time of referral }\end{array}$ & $\begin{array}{l}\text { General observations } \\
\text { Level } 2 \\
\text { Level } 3 \\
\text { Level } 4\end{array}$ & $\begin{array}{l}9 \\
1 \\
6 \\
2\end{array}$ & $\begin{array}{l}50 \\
5.5 \\
33 \\
11\end{array}$ \\
\hline Mental Health Act Status & $\begin{array}{l}\text { Informal } \\
\text { Section }\end{array}$ & $\begin{array}{l}5 \\
13\end{array}$ & $\begin{array}{l}28 \\
72\end{array}$ \\
\hline
\end{tabular}


Table 2. Number of re-admissions to the wards

\section{Ward/Time}

\begin{tabular}{|c|c|c|c|c|c|c|c|c|c|c|}
\hline & \multicolumn{2}{|c|}{ Female Ward 1} & \multicolumn{2}{|c|}{$\begin{array}{l}\text { Female } \\
\text { Ward } 2\end{array}$} & \multicolumn{2}{|c|}{$\begin{array}{c}\text { Male Ward } \\
1\end{array}$} & \multicolumn{2}{|c|}{$\begin{array}{c}\text { Male Ward } 2 \\
2\end{array}$} & \multicolumn{2}{|c|}{$\begin{array}{c}\text { Male Ward } \\
\mathbf{3} \\
\end{array}$} \\
\hline Time point & 1 & 2 & 1 & 2 & 1 & 2 & 1 & 2 & 1 & 2 \\
\hline $\begin{array}{c}\text { Readmissions } \\
\text { N }(\%)\end{array}$ & $\begin{array}{c}40 \\
(28.8)\end{array}$ & $\begin{array}{c}15 \\
(8.6)\end{array}$ & $\begin{array}{c}44 \\
(28.8)\end{array}$ & $\begin{array}{c}24 \\
(19.7)\end{array}$ & $\begin{array}{c}19 \\
(21.3)\end{array}$ & $\begin{array}{c}10 \\
(9 / 1)\end{array}$ & $\begin{array}{c}15 \\
(15.6)\end{array}$ & $\begin{array}{c}39 \\
(26.4)\end{array}$ & $\begin{array}{c}18 \\
(13.1)\end{array}$ & $\begin{array}{c}8 \\
(8.7)\end{array}$ \\
\hline
\end{tabular}

Time 1= Feb-July 2017; Time 2= Feb-July 2018

Table 3. Analysis of risk management approaches

\begin{tabular}{|c|c|c|c|c|c|c|}
\hline \multirow[b]{2}{*}{ Category } & \multicolumn{2}{|c|}{$\begin{array}{l}\text { Female Ward } 1 \\
\qquad(\mathrm{~N}=336)\end{array}$} & \multicolumn{2}{|c|}{$\begin{array}{c}\text { Female Ward } 2 \\
\qquad(\mathrm{~N}=\mathbf{3 1 2})\end{array}$} & \multicolumn{2}{|l|}{ TOTAL } \\
\hline & $\begin{array}{c}\text { Time 1 } \\
(\mathrm{N}=190)\end{array}$ & $\begin{array}{c}\text { Time } 2 \\
(\mathrm{~N}=146)\end{array}$ & $\begin{array}{c}\text { Time 1 } \\
(\mathrm{N}=159)\end{array}$ & $\begin{array}{c}\text { Time 2 } \\
(\mathrm{N}=153)\end{array}$ & $\begin{array}{c}\text { Time } 1 \\
(\mathrm{~N}=348)\end{array}$ & $\begin{array}{r}\text { Time } 2 \\
(\mathrm{~N}=300)\end{array}$ \\
\hline $\begin{array}{l}\text { C1: Low level } \\
\text { intervention }\end{array}$ & 35.3 & 41.8 & 25.8 & 41.2 & 31 & 41 \\
\hline $\begin{array}{l}\text { C2: Enhanced } \\
\text { observations }\end{array}$ & 12.6 & 12.3 & 13.2 & 11.1 & 12.9 & 11.6 \\
\hline C3: Manual restraint & 27.9 & 20.5 & 38.4 & 30 & 32.8 & 25.3 \\
\hline C4: Rapid tranquilisation & 38.4 & 39 & 35.8 & 39.2 & 37.4 & 39 \\
\hline $\begin{array}{c}\text { C5: Removal of } \\
\text { objects/substances that } \\
\text { can be used to (self-) } \\
\text { harm }\end{array}$ & 18.9 & 21.9 & 17.6 & 5.3 & 18.4 & 13.3 \\
\hline & 7.4 & 4.1 & 11.9 & 7.2 & 9.5 & 5.7 \\
\hline
\end{tabular}




\begin{tabular}{c|l|l|l|l|l|l}
\hline $\begin{array}{c}\text { C6: Involvement of other } \\
\text { services }\end{array}$ & & & & & & \\
\hline
\end{tabular}

Time 1= June-November 2017; Time 2= December-May 2018 


\section{Supplementary material}

\section{Specialist Psychologist Role's key duties and responsibilities}

1. To complete thorough psychological assessments and formulations in order to inform a patient's care planning and risk management in the ward.

2. To complete diagnostic assessments and reports to provide 'diagnostic clarity', involving the use of the Structured Clinical Interview for DSM-5 (SCID-5) and other diagnostic interviews and psychometric tests, as appropriate, to inform a patient's diagnosis and recommendations for intervention.

3. To attend professionals' meetings, ward rounds and other multidisciplinary team (MDT) meetings to offer consultation.

4. To complete one to one interventions with patients focusing on reducing risk informed by CBT and DBT approaches.

5. To carry out individual consultation with psychologists, psychiatrists and other members of the MDT where appropriate, regarding assessment and management of the case.

6. To provide teaching, training and ongoing support for MDT on working with people who have a PD diagnosis and on assessing and managing risk.

7. To provide community follow-up and improve pathways between inpatient services and specialist community services (e.g. personality disorder services).

8. To offer support to family and friends of patients identified as 'high risk' (e.g. psychoeducation, brief supportive therapy). 
Table 4: Coding Scheme

\begin{tabular}{|c|c|c|}
\hline Category & Definition & Examples \\
\hline C1: Low level intervention & $\begin{array}{l}\text { The use of: reassurance, } \\
\text { distraction and calming } \\
\text { techniques to encourage } \\
\text { relaxation, verbal de- } \\
\text { escalation, persuasion, staff } \\
\text { change, reduce stimulation or } \\
\text { medical review. }\end{array}$ & $\begin{array}{l}\text { "Staff verbally de-escalate the } \\
\text { situation and patient was } \\
\text { encouraged to go to her } \\
\text { bedroom." } \\
\text { "the patient was escorted to the } \\
\text { treatment room where the } \\
\text { wounds were dressed up. She } \\
\text { was spoken reassuringly which } \\
\text { helped her calming down". } \\
\text { "patient was verbally de- } \\
\text { escalated in the form of calm } \\
\text { talking, reassurance and staff } \\
\text { change" }\end{array}$ \\
\hline C2: Enhanced observations & $\begin{array}{l}\text { The patient was assigned a } \\
\text { level of observation other than } \\
\text { 'general observations', such as } \\
\text { 'level 2' (Intermittent } \\
\text { Observation every } 15 \text { to } 30 \\
\text { minutes), 'level 3' (Continuous } \\
\text { - Within Eyesight) or 'level 4' } \\
\text { (Continuous - Within Arm's } \\
\text { Length) }\end{array}$ & $\begin{array}{l}\text { "she settled down and } \\
\text { commenced on level } 4(2: 1) \\
\text { observation." } \\
\text { "level of observation enhanced } \\
\text { to level } 31: 1 "\end{array}$ \\
\hline C3: Manual restraint & $\begin{array}{l}\text { The person was physically held } \\
\text { by staff to prevent or restrict } \\
\text { movement. }\end{array}$ & $\begin{array}{l}\text { "patient was restrained by } \\
\text { secure holds and taken to her } \\
\text { bed area". } \\
\text { "She refused all oral } \\
\text { medication. She was } \\
\text { escorted to her bedroom by } \\
\text { staff using safe pmva } \\
\text { technique (level } 2 \text { hold), } \\
\text { offered oral medication once }\end{array}$ \\
\hline
\end{tabular}




\begin{tabular}{|c|c|c|}
\hline & & $\begin{array}{l}\text { again but continued to refuse, } \\
\text { she was restrained safely by } \\
\text { female staff for the } \\
\text { administration of im." } \\
\text { "restrained safely by female } \\
\text { staff for the administration of } \\
\text { PRN medication" }\end{array}$ \\
\hline C4: Rapid tranquilisation & $\begin{array}{l}\text { The use of medication to } \\
\text { calm/sedate the person with the } \\
\text { purpose of controlling extreme } \\
\text { agitation, aggression and } \\
\text { potentially violent behaviour. }\end{array}$ & $\begin{array}{l}\text { "she was restrained and was } \\
\text { given prn im promethazine } \\
50 \mathrm{mg} \text { ". } \\
\text { "prn medication was } \\
\text { administered intramuscularly } \\
\text { due to escalating risk } \\
\text { behaviour." } \\
\text { "She was restrained using } \\
\text { friendly come along and was } \\
\text { given prn im lorazepam } 1 \mathrm{mg} \\
\text { and im haloperidol 5mg with } \\
\text { good effects." }\end{array}$ \\
\hline $\begin{array}{l}\text { C5: Removal of objects or } \\
\text { substances that can be used to } \\
\text { (self-) harm }\end{array}$ & $\begin{array}{l}\text { Staff removed objects from the } \\
\text { patient, including ligatures } \\
\text { (e.g. bed linen, clothing, etc.); } \\
\text { objects used to cut (e.g. broken } \\
\text { glass, knife, razor blade, etc.) } \\
\text { or burn (e.g. lighter) and } \\
\text { substances used to poison (e.g. } \\
\text { cleaning products, medication, } \\
\text { etc.) }\end{array}$ & $\begin{array}{l}\text { "Staff watching her from the } \\
\text { door quickly intervened and } \\
\text { took the disposable underwear } \\
\text { off her." } \\
\text { "broken pieces of glass were } \\
\text { taken from her" } \\
\text { "After room search: staff } \\
\text { found } 489 \text { brown tablets in a } \\
\text { white paper bag and these were } \\
\text { taken away" }\end{array}$ \\
\hline
\end{tabular}




\begin{tabular}{|l|l|l|}
\hline & & $\begin{array}{l}\text { "staff intervene straight away } \\
\text { and took the knife away from } \\
\text { the patient" }\end{array}$ \\
\hline $\begin{array}{l}\text { C6: Involvement of other } \\
\text { services }\end{array}$ & $\begin{array}{l}\text { Staff liaised with external } \\
\text { services, including; ambulance, } \\
\text { hospital, police or the } \\
\text { safeguarding team. }\end{array}$ & $\begin{array}{l}\text { "She was placed on a recovery } \\
\text { position vital signs done and } \\
\text { ambulance called". } \\
\text { "She was taken to X hospital } \\
\text { where she was attended to and } \\
\text { declared medically cleared" } \\
\text { "The police was called and } \\
\text { attended the ward. They took } \\
\text { statement from patient and her } \\
\text { visitor. }\end{array}$ \\
\hline
\end{tabular}


Table 5: Type, Severity and Detail of 'risk related incidents' recorded on Datix $(\mathrm{N}=648)$

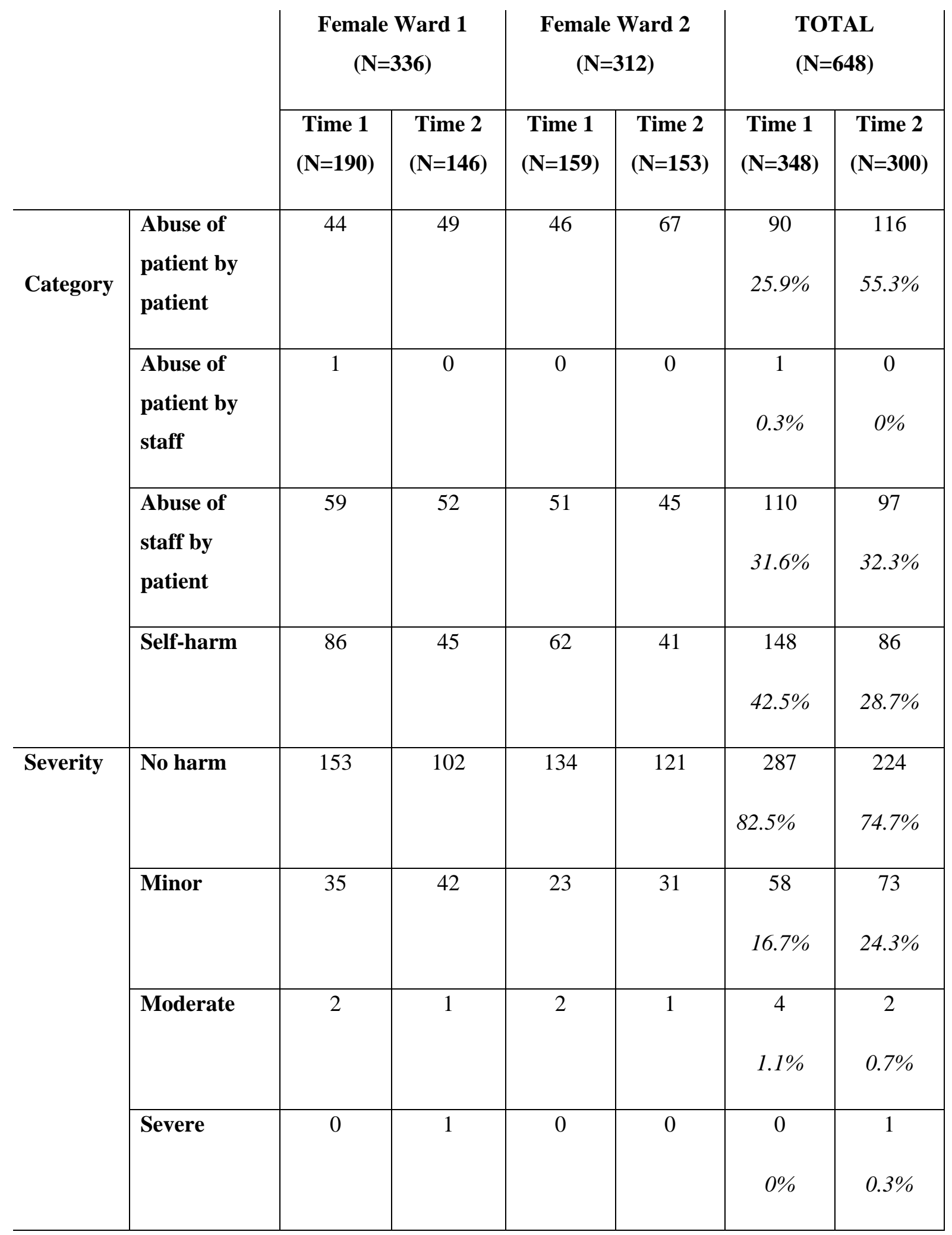




\begin{tabular}{|c|c|c|c|c|c|c|c|}
\hline \multirow[t]{10}{*}{$\begin{array}{l}\text { Detail of } \\
\text { event }\end{array}$} & $\begin{array}{l}\text { Aggression } \\
\text { to the } \\
\text { environment }\end{array}$ & 8 & 14 & 13 & 7 & $\begin{array}{l}21 \\
6 \%\end{array}$ & $\begin{array}{l}21 \\
6 \%\end{array}$ \\
\hline & $\begin{array}{l}\text { Physical } \\
\text { abuse, } \\
\text { assault or } \\
\text { violence }\end{array}$ & 61 & 71 & 54 & 84 & $\begin{array}{l}115 \\
33 \%\end{array}$ & $\begin{array}{c}155 \\
51.7 \%\end{array}$ \\
\hline & $\begin{array}{l}\text { Attempted } \\
\text { suicide }\end{array}$ & 25 & 16 & 31 & 10 & $\begin{array}{c}56 \\
35.6 \%\end{array}$ & $\begin{array}{c}26 \\
8.7 \%\end{array}$ \\
\hline & Verbal abuse & 5 & 1 & 5 & 0 & $\begin{array}{c}10 \\
2.3 \%\end{array}$ & $\begin{array}{c}1 \\
0.3 \%\end{array}$ \\
\hline & Sexual abuse & 0 & 0 & 1 & 2 & $\begin{array}{c}1 \\
0.3 \%\end{array}$ & $\begin{array}{c}2 \\
0.7 \%\end{array}$ \\
\hline & $\begin{array}{l}\text { Self-harming } \\
\text { behaviour }\end{array}$ & 48 & 24 & 22 & 10 & $\begin{array}{c}70 \\
20.1 \%\end{array}$ & $\begin{array}{c}34 \\
11.3 \%\end{array}$ \\
\hline & $\begin{array}{l}\text { Refusal of } \\
\text { medication }\end{array}$ & 10 & 4 & 9 & 18 & $\begin{array}{c}19 \\
5.5 \%\end{array}$ & $\begin{array}{c}22 \\
6.3 \%\end{array}$ \\
\hline & Racial & 0 & 3 & 4 & 1 & $\begin{array}{c}4 \\
1.1 \%\end{array}$ & $\begin{array}{c}4 \\
1.3 \%\end{array}$ \\
\hline & Drug use & 3 & 1 & 0 & 3 & $\begin{array}{c}3 \\
0.9 \%\end{array}$ & $\begin{array}{c}4 \\
1.3 \%\end{array}$ \\
\hline & Other & 30 & 12 & 20 & 18 & $\begin{array}{c}50 \\
14.4 \%\end{array}$ & $\begin{array}{c}30 \\
10 \%\end{array}$ \\
\hline
\end{tabular}

Time 1= June-November 2017 (before the introduction of the SPECIALIST

PSYCHOLOGIST) 
Figure 1. Average length of stay (ALoS) prior and after the specialist psychologist

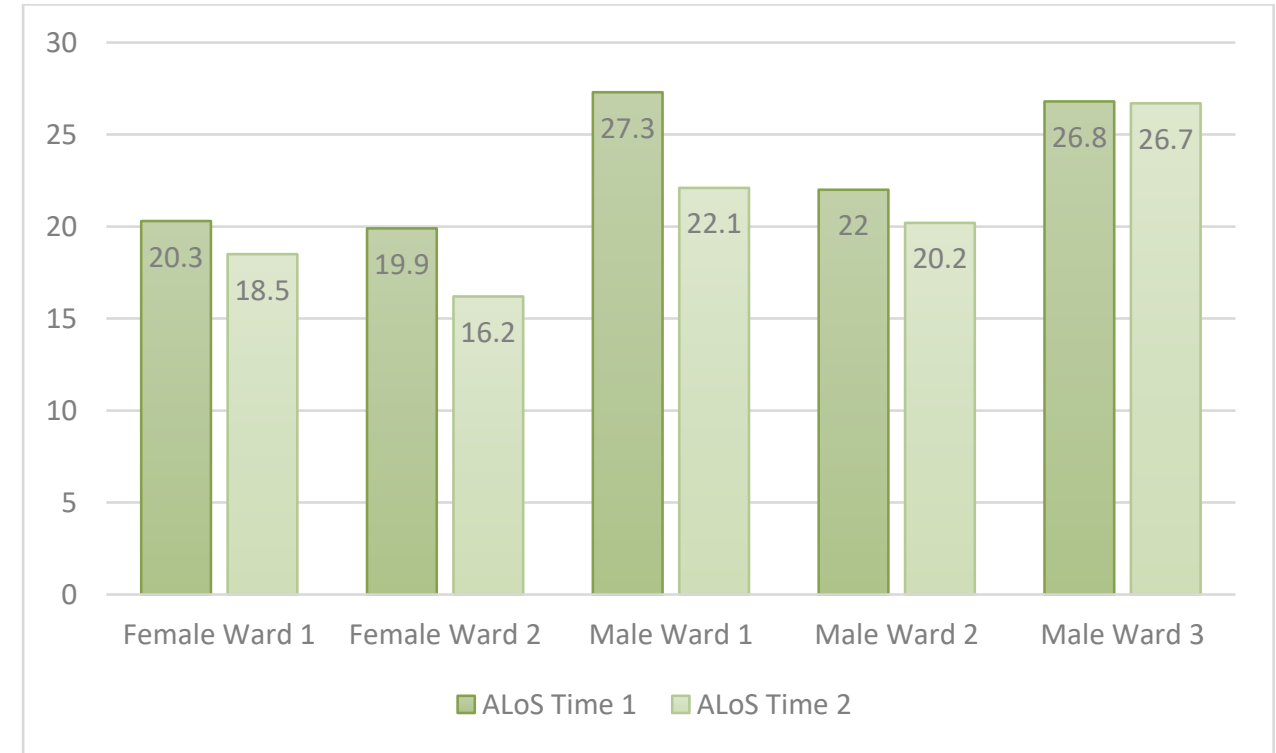

Time 1= Feb-July 2017; Time 2= Feb-July 2018

Figure 2. Number of times a restrictive intervention was recorded

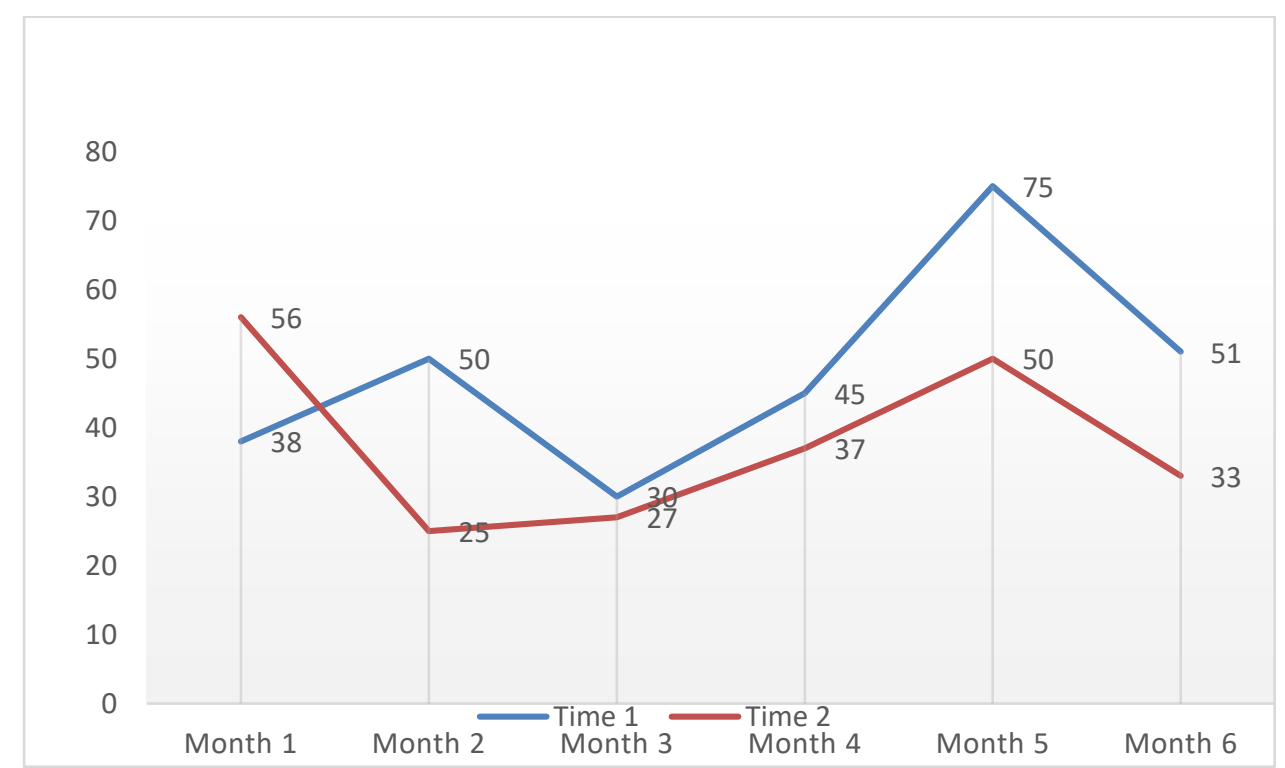

